\title{
Comparative study of fixation of intertrochanteric fracture of the femur by proximal femur nail versus dynamic hip screw
}

\author{
H. B. Shivakumar, Ramalingaiah Yatish*, Channappa T. Seetharam, \\ Manju Jayaram, Amith Kamath K.,
}

Department of Orthopaedics, Kempegowda Institute of Medical Sciences, V. V. Puram, Bangalore, Karnataka, India

Received: 02 February 2020

Revised: 16 April 2020

Accepted: 17 April 2020

\section{*Correspondence:}

Dr. Ramalingaiah Yatish,

E-mail: yatish2005@gmail.com

Copyright: (c) the author(s), publisher and licensee Medip Academy. This is an open-access article distributed under the terms of the Creative Commons Attribution Non-Commercial License, which permits unrestricted non-commercial use, distribution, and reproduction in any medium, provided the original work is properly cited.

\begin{abstract}
Background: Intertrochanteric fractures are common in old age group, but uncommon in younger age group. The goal of treatment of intertrochanteric fractures is restoration to pre-injury status at the earliest. The purpose of this study is to compare the functional outcome of the two fixation devices proximal femur nail (PFN) and dynamic hip screw available for intertrochanteric fractures in terms of the eventual functional outcome of the patient.

Methods: Prospective study of 30 cases of Intertrochanteric fractures admitted and operated in KIMS hospital from November 2017 to May 2019. Follow-up of these patients was done at 6 weeks, 12 weeks and 24 weeks with functional evaluation was done using Harris hip score at the 24th week.

Results: The results at the end of 24 weeks follow-up were calculated by the Harris hip score were better with the PFN. $66.7 \%$ of the patients operated with PFN gave excellent results as compared to $60 \%$ of patients operated with dynamic hip screw (DHS).

Conclusions: We conclude that the use of PFN for the fixation of trochanteric fractures against the proven DHS offered better results along with a few advantages. PFN required smaller incision, shorter duration of surgery, less blood loss and faster recovery and better functional outcome at the end of 24 weeks. But still PFN is technically more demanding than the DHS and was found to have longer fluoroscopy exposure.
\end{abstract}

Keywords: Intertrochanteric fractures, Proximal femur nail, Dynamic hip screw, Harris hip score

\section{INTRODUCTION}

Intertrochanteric fractures are common in old age group and uncommon in the younger age group. These fractures readily unite with conservative treatment with malunion. In trochanteric fractures treated conservatively malunion with coxa vara deformity resulting in shortening of limb and limp are commonly seen. ${ }^{1}$ Various operative procedures with different implants have been described for the treatment of intertrochanteric fractures. These fractures were given little attention in the past, as they would heal without any active intervention as they occur through the cancellous bone with excellent blood supply. But conservative management resulted in malunion of the femur with varus deformity, external rotation and shortening which resulted in short limb gait and due to complications of recumbence and prolonged immobilization lead to a higher morbidity and mortality. The purpose of our study was to compare the two-time tested devices, dynamic hip screw (DHS) and proximal femur nail (PFN) in terms of the final outcome with respect to union of the fracture, functional outcome and complications. 


\section{METHODS}

This prospective study was conducted in Kempegowda Institute of Medical Sciences, Bangalore, between November 2017 to May 2019. Consent of all patients included in the study was taken. The study consisted of total 30 patients, 15 of which were treated by PFN and 15 by DHS.

\section{Inclusion criteria}

All patients 18 years above who sustained intertrochanteric fractures were selected.

\section{Exclusion criteria}

Patients with pathological fractures, patients unfit for surgery and patients not willing for surgery were excluded from our study.

Our study was to compare the two methods of fixation of intertrochanteric fractures with respect to duration of surgery, fluoroscopy time, blood loss, duration of hospital stay, fracture union, functional outcome. Once the patient was admitted, radiographs of the pelvis with both hips in AP view was taken. The fractures were classified using Boyd and Griffin classification. ${ }^{2}$ Follow-up of these patients was done at 6 weeks, 12 weeks and 24 weeks with functional evaluation done using Harris hip score at the 24th week.

\section{Statistical methods}

Descriptive and inferential statistical analysis has been carried out in the present study. Results on continuous measurements are presented on mean \pm SD (min-max) and results on categorical measurements are presented in number (\%). Significance is assessed at 5\% level of significance. The following assumptions on data is made, assumptions dependent variables should be normally distributed, samples drawn from the population should be random, cases of the samples should be independent. Student t test (two tailed, independent) has been used to find the significance of study parameters on continuous scale between two groups (Inter group analysis) on metric parameters. Leven`s test for homogeneity of variance has been performed to assess the homogeneity of variance.

Chi-square/Fisher exact test has been used to find the significance of study parameters on categorical scale between two or more groups, non-parametric setting for qualitative data analysis. Fisher exact test used when cell samples are very small.

\section{Statistical software}

The statistical software namely SPSS 22.0, and R environment ver.3.2.2 were used for the analysis of the data and Microsoft word and Excel have been used to generate graphs, tables etc.

\section{Procedure}

Positioning: The positioning of the patients is in a similar manner for both the procedures. Patient is places supine on a fracture table with the unaffected limb placed flexed and abducted in a well leg holder with a centre post for counter traction, allowing the easy movement and placement of the C-arm.

Reduction: Intertrochanteric fractures can be reduced in neutral, slight internal rotation or external rotation along with adduction of the affected limb. Rotation depends on the comminution of posterior cortex. Internally rotating the involved femur 10-15 degrees offsets the anteversion of the femoral neck and provides a true AP of the proximal femur.

Draping: The skin over the hip prepared after a scrub with $7.5 \%$ povidone iodine solution and chlorhexidine with cetrimide antiseptic solutions. The lateral aspect of the hip from the iliac crest to the distal thigh squared off with towels and drapes.

Incision: For the DHS, the incision extends from the tip of the greater trochanter distally subsequently the underlying Fascia Lata is incised and muscle dissected to expose the lateral cortex of the tibia. The incision for PFN however, extends proximally from the tip of the greater trochanter.

Fixation: For the DHS, using an angle guide at $130^{\circ}$ or $135^{\circ}$, a guide wire is passed into the head of the femur till $5 \mathrm{~mm}$ into the subchondral bone. Once the position is checked under C-arm, the reaming of the femur is done using a triple reamer followed by the passage of the lag screw. Once the Lag screw is in the center-center position, the plate is then latched onto the lag screw and the plate is made to sit on the lateral cortex of the femur. The screw holes are then drilled and fixation with screws is done. Finally, the locking of the lag screw with the compression screw is done.

For the PFN, an entry point is made on the tip of the greater trochanter using a bone awl. This is followed by a ball tip guide wire. The positioning is checked continuously with a C-arm. Once satisfactorily passed, a reaming of the proximal femur is done with a rigid reamer. The nail is then passed along the guide wire with the help of the angled jig. Once in position, the marking is done for the 2 drill sleeves to be passed. Incision is made and the drill sleeves are passed till flush with the lateral cortex of the femur. 2 guide wires are passed till subchondral bone. The proximal guide wire is placed $10-15 \mathrm{~mm}$ lesser than the distal guide wire. The reaming is done with a drill-bit. The distal lag screw fixation is done up to $5 \mathrm{~mm}$ into the subchondral bone. The de-rotation screw selected is $10-15$ $\mathrm{mm}$ shorter than the lag screw. Once the 2 screws are tightened, distal locking is done with a $4.5 \mathrm{~mm}$ cortical screw. 

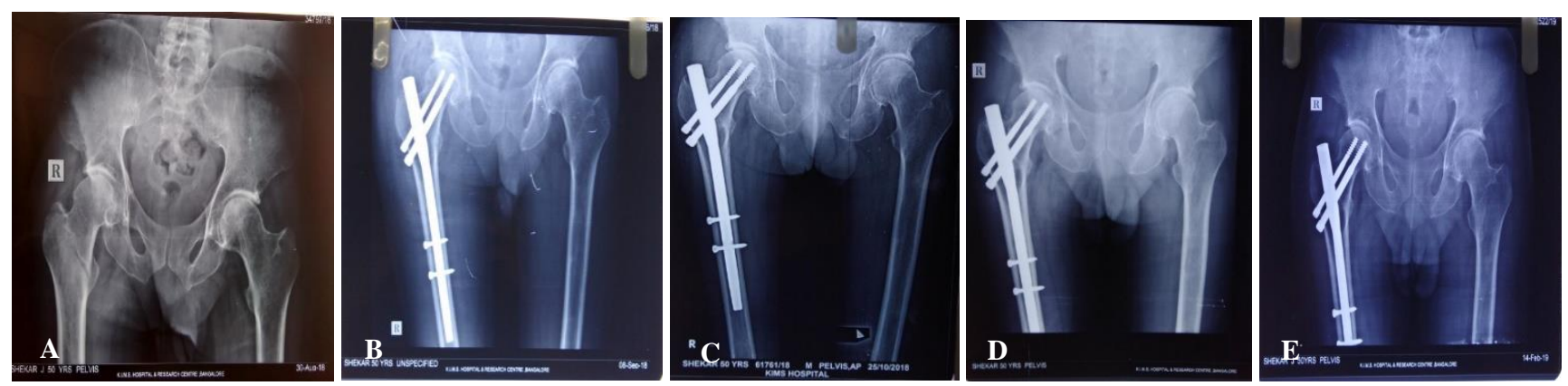

Figure 1: Pre-op, post op and follow up of PFN fixation, (A) pre-op, (B) post-op, (C) 6 weeks, (D) 12 weeks and (E) 24 weeks.
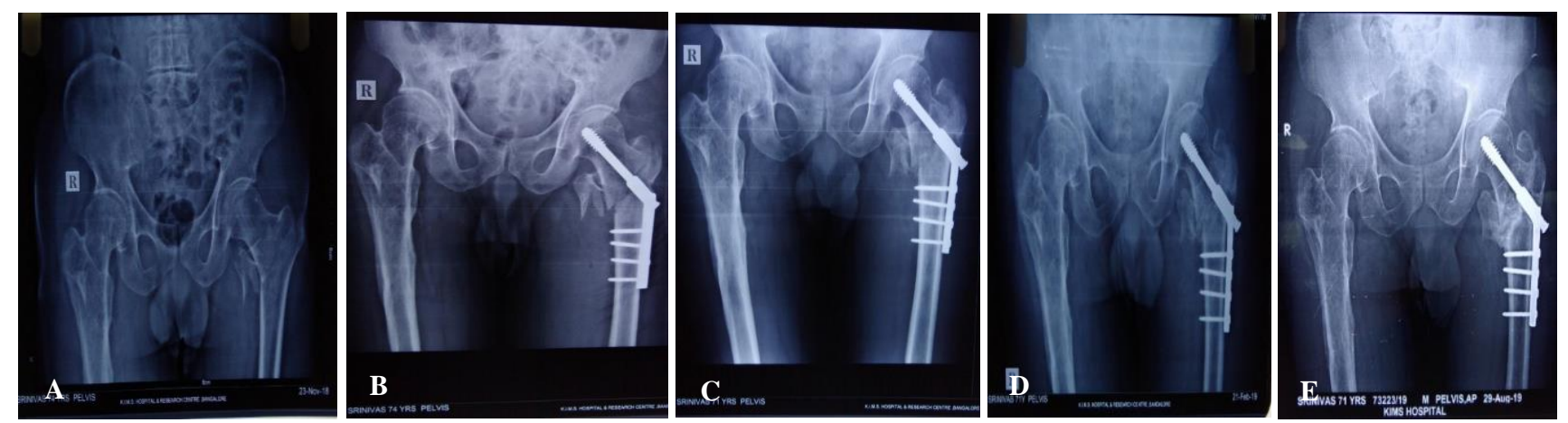

Figure 2: Pre-op, post op and follow up of DHS fixation, (A) pre-op, (B) post-op, (C) 6 weeks, (D) 12 weeks and (E) 24 weeks.
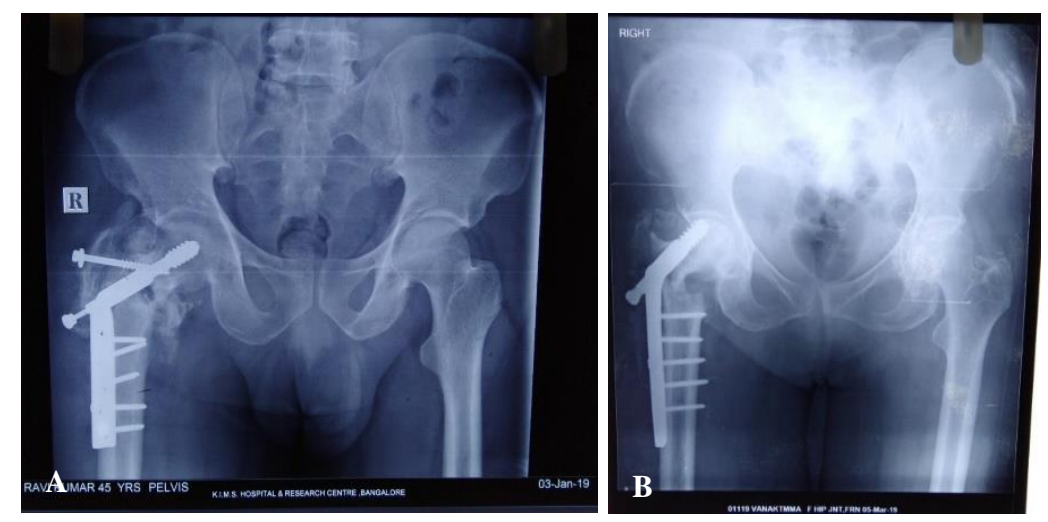

Figure 3: Complications, (A) DHS implant failure and (B) DHS screw cut out.

Closure: The tensor fascia lata is approximated and closed with interrupted sutures. The wound is then closed in layers.

Post-operative protocol: All patients were given IV antibiotics for 5 days. Mobilization of hip and knee was done as tolerated between postoperative day (POD) 3 to POD 5. Suture removal was done at POD 12. Patients were kept on non-weight bearing mobilization for 6 weeks followed by partial weight bearing and full weight bearing by weeks.

\section{RESULTS}

In this study, most patients belonged to the $41-50$ years age group. The mean age of PFN patients was 56.40 years and for those DHS patients was 59.93 years. Both the genders were equally affected. Majority (73.3\%) of cases occurred as a result of trivial trauma such as slip and fall, followed by road traffic accidents $(16.7 \%)$ and fall from height (10\%). Right sided fractures $(70 \%)$ were found to be more common than left sided fractures $(30 \%)$. All fractures were graded according to Boyd and Griffin classification and it was found that type 2 was most common (50\%) followed by type $3(30 \%)$ and type $4(20 \%)$. The mean duration of 
surgery was shorter for the PFN group compared to the DHS group (76.33 min) (Table 1).

However, the fluoroscopy time for the DHS group (1.80 mins) was shorter when compared to PFN group (4.07 min). The Blood loss in the PFN group (109.33 ml) significantly lesser when compared to the DHS group (225 $\mathrm{ml})$.

Table 1: Patients characteristics.

\begin{tabular}{|lll|}
\hline Characteristics & PFN group & DHS group \\
\hline Mean age (years) & 56.40 & 59.93 \\
\hline $\begin{array}{l}\text { Gender } \\
\text { predisposition }\end{array}$ & $\begin{array}{l}\text { Male-8; } \\
\text { female-7 }\end{array}$ & $\begin{array}{l}\text { Male-7; } \\
\text { female-8 }\end{array}$ \\
\hline Side predisposition & $\begin{array}{l}\text { Right-12, } \\
\text { left-3 }\end{array}$ & $\begin{array}{l}\text { Right-9, } \\
\text { left-6 }\end{array}$ \\
\hline $\begin{array}{l}\text { Mean duration of } \\
\text { hospital stay (days) }\end{array}$ & 14.40 & 18.47 \\
\hline $\begin{array}{l}\text { Mean duration of } \\
\text { surgery (in min) }\end{array}$ & 54.67 & 76.33 \\
\hline $\begin{array}{l}\text { Mean fluroscopy time } \\
\text { (in min) }\end{array}$ & 4.07 & 1.80 \\
\hline Mean blood loss (ml) & 109.33 & 225 \\
\hline
\end{tabular}

Table 2: Mean duration of union.

\begin{tabular}{|llll|}
\hline Union & PFN & DHS & Total \\
\hline $\begin{array}{l}\text { Non- } \\
\text { union }\end{array}$ & $0(0)$ & $\mathbf{N}(\%)$ & $\mathbf{N}(\%)$ \\
\hline Union & $15(100)$ & $12(80)$ & $27(90)$ \\
\hline 12 weeks & $10(66.7)$ & $5(33.3)$ & $15(50.0)$ \\
\hline 18 weeks & $4(26.7)$ & $6(40.0)$ & $10(33.3)$ \\
\hline 24 weeks & $1(6.7)$ & $1(6.7)$ & $2(6.7)$ \\
\hline Mean \pm SD & $14.40 \pm 3.79$ & $16.00 \pm 3.91$ & $15.11 \pm 3.86$ \\
\hline
\end{tabular}

The average time of union of the fractures was almost equal in the both the groups at 15.11 weeks (PFN group14.40 weeks and DHS group-16.00 weeks) (Table 2).

Although non-union is very rare in intertrochanteric fractures, 3 cases of non-union were recorded at the end of 24 weeks due to screw cut out in 2 patients and implant failure in 1 patient (all 3 cases were of DHS fixation). The average duration of stay of patients in PFN group (14.40 days) was lesser compared to the DHS group (18.47 days).

Table 3: Functional outcome.

\begin{tabular}{|llll|}
\hline \multirow{2}{*}{ Result } & PFN & DHS & Total \\
\hline Excellent & $\mathbf{N}(\boldsymbol{\%})$ & $\mathbf{N}(\boldsymbol{\%})$ & $\mathbf{N}(\boldsymbol{\%})$ \\
\hline Good & $10(66.7)$ & $9(60)$ & $19(63.3)$ \\
\hline Fair & $1(6.7)$ & $3(20)$ & $7(23.3)$ \\
\hline Poor & $0(0)$ & $2(13.3)$ & $3(10)$ \\
\hline
\end{tabular}

The functional outcome however was better in the PFN group with excellent results in $66.7 \%$ patients compared to $60 \%$ in the DHS group (Table 3).

\section{DISCUSSION}

In our study we found that the average age of the patients was 59.93 years. This is consistent with Panagopoulos et al who in their study reported an average age of 61.2 years. ${ }^{3}$ Intertrochanteric fractures are more common in elderly patients. It was also recorded that males and females were equally affected in our study. Saudan et al and Pajarinen et al in their studies noted that females were more affected than males. ${ }^{1,4}$ The higher incidence of intertrochanteric in the elderly due to a trivial trauma is similar to other series such as Hornby et al. ${ }^{5}$ Pajarinen et al also reported that most common cause was trivial trauma similar to the results of our study. ${ }^{1}$ Nuber et al in their study of 129 patients reported that the average duration of surgery for PFN was lesser than that for DHS. ${ }^{6}$ This is mostly because PFN requires smaller incision and the number of screws are less as compared to DHS giving it an advantage.

The fluoroscopy time was found to be much more for the PFN is than that for the DHS similar to that reported by Prasad et al. ${ }^{7}$ The average amount of blood lost in DHS surgery was markedly more than that in PFN surgery comparable to the results reported by Pajarinen et al, Prasad et al and Mundla et al. ${ }^{1,7,8}$ Similar study by Portakal et al resulted in complete union of the fracture within 4 months which is comparable to 15.11 weeks reported in our study. ${ }^{9}$ Functional outcome with PFN was found to be better than DHS for the treatment of intertrochanteric fractures by Pajarinen et al, Nuber et al and also Cruz et al reported that PFN was an efficient means to treat extracapsular proximal femur fractures. ${ }^{1,6,10}$

\section{CONCLUSION}

We conclude that the use of PFN for the fixation of trochanteric fractures against the proven DHS offered better results along with a few advantages. PFN required smaller incision, shorter duration of surgery, less blood loss and faster recovery and better functional outcome at the end of 24 weeks. But still PFN is technically more demanding than the DHS and was found to have longer fluoroscopy exposure.

\section{Funding: No funding sources \\ Conflict of interest: None declared}

Ethical approval: The study was approved by the institutional ethics committee

\section{REFERENCES}

1. Pajarinen J, Lindahl J, Michelsson O, Savolainen V, Hirvensalo E. Pertrochanteric femoral fracture treated with a dynamic hip screw or a proximal femoral nail. J Bone Joint Surg. 2005;87:76-81. 
2. David GL. Fractures of Hip. In: Canale ST, editor. Campbell's Operative Orthopaedics. 10th ed. Mosby; 2003: 2873-2897.

3. Panagopoulos A, Papas M, Papadopoulos AX, Tyllianakis M, Megas P, Lambiris E. Long term results and complications of gamma nail and proximal femoral nail in pertrochanteric hip fractures. J Bone Joint Surg. 2004;86:183.

4. Saudan M, Lubbeke A, Sadowski C, Riand N, Stern R, Hoffmeyer P. Pertrochanteric fractures: is there an advantage to an intramedullary nail? A randomized, prospective study of 206 patients comparing the dynamic hip screw and proximal femoral nail. J Orthop Trauma. 2001;16:386-93.

5. Hornby R, Evans JG, Vardon V. Operative or Conservative Treatment for Trochanteric Fractures of the Femur. J Bone Joint Surg. 1989;71:619-23.

6. Nuber S, Schonweiss T, Ruter A. Stabilization of unstable trochanteric femoral fractures: Dynamic hip screw with trochanteric stabilization plate vs. proximal femoral nail. J Orthop Trauma. 2003;17(4):316-7.

7. Prasad DV. Comparative study between DHS and PFN in the management of trochanteric and subtrochanteric femoral fractures. Int J Orthop Sci. 2017;3(4):106-8.

8. Mundla MKR, Shaik MR, Buchupalli SR, Chandranna B. A prospective comparative study between proximal femoral nail and dynamic hip screw treatment in trochanteric fractures of femur. Int J Res Orthop. 2018;4(1):58-64.

9. Portakal S, Utkan A, Dayican A, Ozkan G, Karaman Y, Tumoz MA. Treatment of trochanteric femoral fractures with the proximal femoral nail. J Bone Joint Surg. 2006;88:183-4.

10. Cruz-Ocaña E, Rodríguez-García MA, GarciaHerrera Taillefer G, Guerado-Parra E. Complications of using PFN nail in the treatment of extracapsular fractures of the proximal femur. J Bone Joint Surg. 2005;87(1):86.

Cite this article as: Shivakumar HB, Yatish R, Seetharam CT, Jayaram M, Amith KK. Comparative study of fixation of intertrochanteric fracture of the femur by proximal femur nail versus dynamic hip screw. Int J Res Orthop 2020;6:717-21. 